\title{
The Challenges of Designing and Implementing Effective Professional Development for Out-of-Field High School Physics Teachers
}

\author{
Lawrence T. Escalada and Julia K. Moeller \\ University of Northern Iowa, Cedar Falls, IA 50614, USA
}

\begin{abstract}
With the existing shortage of qualified high school physics teachers and the current mandate of the No Child Left Behind Act requiring teachers to be "highly qualified" in all subjects they teach, university physics departments must offer content courses and programs that would allow out-of-field high school physics teachers to meet this requirement. This paper will identify how the University of Northern Iowa Physics Department is attempting to address the needs of the high school physics teacher through its course offerings and professional development programs for teachers. The effectiveness of one such physics professional development program, the UNI Physics Institute (UNI-PI), on secondary science teachers' and their students' conceptual understanding of Newtonian mechanics, and the teachers' instructional practices was investigated. Twenty-one Iowa out-of-field high school physics teachers participating in the program were able to complete the physics coursework required to obtain the State of Iowa 7-12 Grade Physics Teaching endorsement. Twelve of the participants completed a two-year program during the 2002 and 2003 summers. Background information, pre- and post-test physics conceptual assessments and other data was collected from participants throughout the Institute. Participants collected pre and post-test conceptual assessment data from their students during the 2002-2003 and 2003-2004 academic years. This comprehensive assessment data revealed the Institute's influence on participants' and students' conceptual understanding of Newtonian Mechanics. The results of this investigation, the insights we have gained, and possible future directions for professional development will be shared.
\end{abstract}

Keywords: High School, Physics Teachers, Professional Development.

PACS: 01.40.Jp

\section{INTRODUCTION}

The No Child Left Behind (NCLB) act mandates that all states must ensure that their teachers are highly qualified by a 2005-06 deadline [1]. To be deemed highly qualified, teachers must have: (1) a bachelor's degree, 2) full state certification or licensure, and 3) prove that they know each subject they teach. However, this original provision of NCLB provides special challenges to rural teachers who teach more than one academic subject and science teachers who are often needed to teach in more than one field of science. Some states allow science teachers who teach more than one field of science to be certified under a general science certification, whiles others require a subject-specific certification (such as physics, biology, or chemistry). As a result, a new flexibility has been provided to recognize these challenges and to provide additional time for these teachers to prove that they are highly qualified. Under this new policy, teachers in eligible, rural districts who are highly qualified in at least one subject will have three years to become highly qualified in the additional subjects they teach.

\section{Highly Qualified in Iowa}

In the state of Iowa, teachers are deemed to be highly qualified if they hold a valid teaching license and are properly endorsed to teach in the areas for which they are assigned [2]. The requirements for the State of Iowa Grades 7-12 physics teaching endorsement is completion of 24 semester hours in physics or 30 semester hours in the broad area of science to include 15 semester hours in physics [3]. An out-of-field high school physics teacher is one who teaches physics but whose science field of speciality is non-physics such as chemistry or biology. In the state of Iowa, a biology teacher or any non-physics science teacher would need to complete 15 semester hours in physics to obtain the State of Iowa 7-12 physics teaching endorsement 
since they would have the number of hours required for the broad area of science.

\section{CURRENT STATE OF HIGH SCHOOL PHYSICS TEACHING}

The Iowa Department of Education has designated Grades 7-12 Science (all subjects) as one of the teacher shortage areas for Iowa [2]. As a result, science teachers in urban areas as well as rural areas would be needed to teach outside their science field of expertise. During the 2003-04 academic year, $88 \%$ of the grades $7-12$ science teaching assignments were taught by highly qualified teachers - those teachers with a teaching endorsement [2]. In 1999 - 2000, of the 437 high school physics teachers (public and private) in the state of Iowa, 81\% were identified as being highly qualified [4]. These results are consistent with the results of a nationally represented sample collected in 1999-2000 by the U.S. Department of Education, National Center for Education Statistics (NCES) [5]. They reported that $17 \%$ percent of high school physics students were being taught by a teacher who lacked a physics major, minor or certification.

According to the 2000-01 High School Physics Survey with a sample of over 3,000 U.S. schools and physics teachers: $32 \%$ of the high school physics teachers surveyed have a physics degree and physics teaching experience, $40 \%$ have no physics degree but extensive physics teaching experience, and $28 \%$ have no physics degree and little physics teaching experience [6]. This 28\% includes those teachers who teach other science fields and math. The same survey found that virtually all physics teachers did major in one of the science or mathematics disciplines and prior surveys have found that all reported taking at least one full year of introductory physics in college.

In regards to high school physics teaching environment, $82 \%$ of the teachers surveyed are the only physics teacher at their school [6]. Fifty four percent of the teachers surveyed indicate they are not members of either the American Association of Physics Teachers or the National Science Teachers Association. These statistics indicate that the majority of high school physics teachers have little or no support from their peers.

\section{UNI PHYSICS DEPARTMENT}

The University of Northern Iowa (UNI) is a statesupported university of approximately 13,000 students founded on a strong liberal arts curriculum with an emphasis on undergraduate education and selected graduate programs. The Physics Department has approximately 10 faculty and 65 undergraduate students. The department offers BA programs in Physics and Physics Teaching and BS programs in Physics, Applied Physics, and Applied Physics/Pre-Engineering. The department provides outreach and service to the community of high school physics students and teachers in the form of a yearly regional Physics Olympics competition for high school physics students as well as courses, workshops, and professional development programs and conferences for high school physics teachers.

These courses have been offered during the summer and on evenings over the Iowa Communications Network (ICN) - interactive television used for distance education - and oncampus on Saturdays during the academic year to accommodate teacher schedules. They have focused on interactive engagement methods [7] of teaching high school physics including PRISMS PLUS [8] which utilizes a modified learning cycle pedagogy [9] and Modeling instruction [10] which utilizes a modeling cycle pedagogy [11] among other methods.

\section{UNI PHYSICS INSTITUTE}

The UNI Physics Department in collaboration with UNI Science Education faculty conducted a professional development program, the UNI Physics Institute, beginning the summer of 2002 and ending the summer of 2003 for a cohort of 21 Iowa secondary science teachers so they could complete the necessary physics course requirements to obtain the 7-12 physics endorsement under one integrated program from one institution in a relatively short period of time. Participants received instruction in both physics content and pedagogy with the focus on interactive engagement methods; were introduced to various resources available to high school physics teachers; were provided financial and instructional support to implement these methods in their classrooms; and were given opportunities to network with colleagues, university physics faculty, and master high school physics teachers including attending and presenting at local and state professional conferences.

The two-year institute was divided into two fourweek summer sessions with one ICN academic seminar sandwiched in between during the 2002-03 academic year. The first summer session focused on traditional first semester topics with the second summer session focused on traditional second semester topics with the emphasis on interactive engagement methods. These methods focused on the learning cycle and modeling cycle pedagogies 
including: PRISMS PLUS [8], Modeling instruction [10], and RealTime Physics (RTP) Modules [12].

The institute implemented a multi-faceted approach to professional development that adhered to the National Science Education Standards for science teacher professional development [13] and the "best practices” for planning, conducting, and evaluating professional development experiences for teachers as identified by Loucks-Horsley et al. [14].

The institute involved 21 participants during its two-year program with 15 during the first year (3 of which left the program after the first year) and 6 new participants were added to the remaining 12 during the second year. The majority of the original 15 participants were teachers whose area(s) of expertise included high school biology and/or chemistry. All 15 were working on completing the requirements for the State of Iowa 7-12 physics teaching endorsement. The 15 participants were clustered almost equally into 3 distinct groups based on the number of physics semester hours completed - those who completed on average 3.9 hours, 6.1 hours, and 8.5 hours. Only 2 of the participants taught physics for more than 3 years. The majority of the participants either taught one year of physics or less or taught two to three years of physics. Twelve of the 15 participants were from rural schools with a majority being outside a mid-sized city ranging in students that numbered from 100 to 350 for the entire school.

\section{Impact on Learning and Teaching}

Participants and their subsequent high school students were administered pre-tests and post-tests to measure their conceptual understanding of force and motion through the Force Concept Inventory (FCI) [15] and the Test of Understanding Graphs in Kinematics (TUG-K) [16]. Table 1 reports participants' and their students' FCI and TUG-K pretest, post-test, and average normalized gains [7].

Table 1 shows participants' and students' FCI and TUG-K scores did increase. Statistically significant differences between the pretest and posttest scores did exist. However, neither the participants nor their students achieved the $80 \%$ correct set as a threshold for mastery of basic Newtonian mechanics by Hestenes et al. for the FCI [15]. The participant and student FCI average normalized gain scores falls within Hake's "Medium-g” course range [7]. Hake considers average gain scores less than 0.3 to be characteristic of traditional courses that rely primarily on passive-student lectures, recipe labs, and algorithmic-problem exams. Hake considers average gains above 0.3 to indicate successful application of interactive engagement instructional methods.

Further analysis of the FCI and TUG-K participant data revealed statistical significant relationships did exist between participants' physics and math background and their conceptual understanding. These results suggest that a professional development program like the institute may be more suitable for participants with some prior background in physics and mathematics.

In addition, further analysis of the FCI and TUG$\mathrm{K}$ student data for both years did show that student scores increased from pre-test to post-test and are statistically different for each test for each year. However, the student scores for both years are nearly identical and are not statistically different.

All participants kept reflection journals during the institute and implementation of the interactive engagement methods in their classroom. In addition, four volunteer participants provided self-reported information about their instructional practices after the institute and after two full years of implementation. These participants reported higher frequency use and confidence level of using interactive engagement instructional methods and materials in their classroom, of using various types of assessments (including white-boarding, Socratic questioning techniques, and performance lab assessments), and of teaching all physics topics.

\section{Insights Gained and Future Directions}

The participant and student learning gains on the FCI and TUG-K indicate successful application of the interactive engagement methods in the participants' classrooms. However, participants' and their students' FCI and TUG-K scores falling below mastery level as well as participant journals indicate that participants had some lingering misconceptions that were not addressed during any of the summer sessions or during implementation. These misconceptions may have been carried over to the following year which could have hindered their ability to teach physics effectively to their students. Unfortunately, the focus of the second summer session moved to other physics topics and a thorough "debriefing" and review/discussion of force and motion did not take place that should have taken place.

Although participants were provided a $\$ 1000$ stipend each summer to purchase instructional resources to implement these methods, many participants indicated they were unable to implement all of these methods to the degree they were introduced and modeled which may have impacted 
TABLE 1. Summary of UNI-PI Participants' and Student FCI and TUG-K Results

\begin{tabular}{|c|c|c|c|c|}
\hline Group & Test & $\begin{array}{c}\text { Pretest } \\
\text { Average } \\
\% \text { Correct }\end{array}$ & $\begin{array}{c}\text { Posttest } \\
\text { Average } \\
\% \text { Correct }\end{array}$ & $\begin{array}{c}\text { Average } \\
\text { Normalized } \\
\text { Gain }\end{array}$ \\
\hline \multirow[t]{2}{*}{ 2002-03 Participants $(\mathrm{N}=15)$} & FCI & 54.4 & 69.1 & 0.32 \\
\hline & TUG-K & 49.5 & 70.5 & 0.42 \\
\hline \multirow[t]{2}{*}{ 2002-03 Students $(\mathrm{N}=175)$} & FCI & 26.3 & 56.9 & 0.41 \\
\hline & TUG-K & 18.1 & 61.2 & 0.52 \\
\hline \multirow[t]{2}{*}{ 2003-04 Students $(\mathrm{N}=77)$} & FCI & 26.5 & 51.8 & 0.35 \\
\hline & TUG-K & 19.9 & 57.6 & 0.47 \\
\hline
\end{tabular}

their teaching effectiveness. For example, many participants were restricted to using one computer and computer laboratory setup as a class demonstration.

Participants with insufficient physics or math background may not gain complete understanding of the concepts addressed in the format used in the physics institute and may have hindered their ability to teach physics effectively to their students. The institute was structured as an 8-week professional development program that focused on interactive engagement type instruction in two 4-week summer sessions. This format may not provide enough time to introduce all of the concepts of an introductory physics course, address participants' preconceptions, and provide instruction on interactive engagement methods. Future programs may need to require prerequisites for those teachers who participate to have sufficient physics and math backgrounds if the current format is to be used and/or provide

\section{REFERENCES}

1. U.S. Department of Education (2005). New No Child Left Behind Flexibility: Highly Qualified Teachers. Retrieved July 7, 2005 from http://www.ed.gov/nclb/methods/teachers/hqtflexibility.html

2. Iowa Department of Education (2005). The State Report Card for the No Child Left Behind. State of Iowa Department of Education.

3. Iowa Board of Educational Examiners (2005). Requirements for Teaching Endorsements. Retrieved July 11, 2005 from http://www.state.ia.us/boee/

4. T. Heiting (2001). Private communication with the State of Iowa Science Consultant.

5. U.S. Department of Education, National Center for Education Statistics (2002). Qualifications of the public school teacher workforce: prevalence of out-offield teaching, 1987-88 to 1999-2000. Available online at http://nces.ed.gov/programs/quarterly/vol 4/4_3/2_2.asp

6. M. Neuschatz \& M. McFarling (2003), Broadening the Base: High School Physics Education at the Turn of a New Century, American Institute of Physics: College Park, MD.

7. R.R. Hake (1998). "Interactive-engagement methods versus traditional methods: A six-thousand-student survey of mechanics test data for introductory physics courses.” American Journal of Physics, 66(1), 64-74. remediation and enrichment for those who need it.

Direct classroom support during classroom implementation of interactive engagement methods similar to an internship-style approach [15] and continued instruction and professional development opportunities for these teachers beyond the institute may be needed to positively impact teacher and student conceptual learning. The need for coherent and relevant professional development programs for out-of-field high school physics teachers seeking a physics teaching endorsement is evident with the existing shortage of high school physics teachers and with the current NCLB mandates. The challenge for physics departments is not to offer quick, piecemeal solutions to the problem but coherent, long-term solutions that will effectively address the needs the of the out-of-field teacher and will have positive impact on teacher and student conceptual learning and teacher instructional practice for years to come.

8. T.M. Cooney, L.T. Escalada, \& R.D. Unruh (2005). PRISMS (Physics Resources and Instructional Strategies for Motivating Students) PLUS. Centre Pointe Learning: Fairfield, Ohio.

9. R. Karplus (1977). "Science teaching and the development of reasoning." Journal of Research in Science Teaching, 14(2), 169-175.

10. M. Wells, D. Hestenes, \& G. Swackhamer (1995). “A modeling method for high school physics instruction." American Journal of Physics, 63(7), 606-619.

11. D. Hestenes (1987). "Toward a modeling theory of physics instruction.” American Journal of Physics, 55(5), 440-454.

12. D. Sokoloff, P. Laws, \& R. Thornton. (2002). RealTime Physics Modules. John Wiley \& Sons, Inc.

13. National Research Council (1996). National Science Education Standards. National Academy Press: Washington, D.C.

14. S. Loucks-Horsely, P.W. Hewson, N. Love, \& K.E. Stiles. (1998). Designing professional development for teachers of science and mathematics Corwin Press: Thousand Oaks, CA.

15. D. Hestenes, M. Wells, \& G. Swackhamer (1992). "The force concept inventory." The Physics Teacher, 30, 141-158.

16. R. Beichner (1994). "Testing student interpretation of kinematics graphs.” American Journal of Physics, 62(8), 750-762. 
